\title{
A High Temperature Light Scattering; Molecular Weight Determination of Poly(phenylene sulphide)
}

\author{
Masahiro Obasa, ${ }^{*}$ Hirokazu NaKamura, ${ }^{* *}$ Masami TaKasaka, ${ }^{* * *}$ \\ Tadaya KATO, ${ }^{* * * *}$ and Mitsuru NAGASAWA
}

Toyota Technological Institute, Hisakata, Tempaku-ku, Nagoya 468, Japan

(Received September 11, 1992)

\begin{abstract}
A light scattering apparatus convenient for use at high temperatures was constructed. Intensities of scattered light are measured with a photon counter. Weight-average molecular weights of linear poly(phenylene sulphide)s and then their intrinsic viscosity-molecular weight relationship were determined in 1-chloronaphthalene at $220^{\circ} \mathrm{C}$. Moreover, it is shown that a heat-treated poly(phenylene sulphide) has a lower intrinsic viscosity than the linear one with the same molecular weight, probably because of its branching or cross-linking structure.

KEY WORDS Poly(phenylene sulphide) / Light Scattering / Viscosity

Equation /
\end{abstract}

Measurements of average molecular weights and molecular weight distribution of macromolecules are no doubt most important in studying physical and mechanical properties of linear polymer materials. In the case of most commodity polymers, which are made of backbones as flexible as poly(styrene) (PS), those molecular characteristics can easily be, at least approximately, estimated from size exclusion chromatography (SEC) using standard PS as reference. Recently, however, attention is given to molecular weights of some new engineering plastics such as poly(phenylene sulphide) (PPS). They are not usually soluble in ordinary solvents at room temperature and often have backbones stiffer than PS, so that proper reference polymers may not always be found in their SEC. In particular, PPS is usually heat-treated in the presence of oxygen to increase its melt viscosity. Chemical reactions occurring in the heat-treatment were studied by various researchers. ${ }^{1-5}$ It is highly likely that crosslinking or branching reactions are involved in the heat treatment. Thus, the direct measurement of molecular weight by high temperature light scattering (LS) seems to be highly desired for some new engineering plastics. It is more satisfactory if the apparatus can be used in connection with SEC. In addition, since new engineering plastics usually have low molecular weights, the LS apparatus should be designed to have rather high sensitivity.

SEC of PPS were studied by Stacy, ${ }^{6}$ Kinugawa, ${ }^{7}$ and Housaki and Satoh $^{8}$ using their own concentration detectors. Weight average molecular weights were calculated using standard PS as reference.

* Tosoh Co., Ltd. Polymer Research Laboratories, Yokkaichi-shi 510, Japan

** Nippondenso Co., Ltd., Showa-cho, Kariya-shi 448, Japan

*** KOFU KONICA Co., Ltd., Misaka-cho, Higashiyatsushiro-gun, Yamanashi 406, Japan

**** Department of Chemistry for Materials, Mie University, Kamihama-cho, Tsu-shi 514, Japan 


\section{EXPERIMENTAL}

\section{Samples}

The PPS samples used were provided from Tosoh Co., Ltd. Sample No. $1-5$ are believed to be linear polymers. They were dissolved in 1-chloronaphthalene at $230-240^{\circ} \mathrm{C}$ in the nitrogen atmosphere and cooled to room temperature to be colloidal solutions or slurries, which are used for LS measurements as explained below. ${ }^{6}$ Their concentrations, which were calculated from the weights of the samples dissolved, were in the range of $0.1-$ $0.5 \%$. Sample No. B1 was prepared by stirring a linear PPS powder at about $260^{\circ} \mathrm{C}$ for 6.5 hours in a rotating kiln, that is, in the presence of air. Therefore, the sample contained microgels at its crude state. The crude sample of No. B1 was dissolved in 1chloronaphthalene and filtered through a membrane filter, Milipore FHUP (pore size $0.45 \mu \mathrm{m}$ ), to remove the microgels. The purified sample of No. Bl may still have a cross-linked or branched molecular structure. Concentrations of sample No. B1 in the purified solutions were determined by weight after drying. Sample No. B2 was prepared by polymerizing $p$-dichlorobenzene with addition of trichlorobenzene to introduce branching into PPS. Since no appreciable amount of microgels was found in sample No. B2, the sample was treated in the same way as linear PPS.

The solvent used is 1-chloronaphthalene of Tokyo Kasei Kogyo Co., Ltd., which was purified by distillation under reduced pressure. Toluene of the HPLC-grade and benzene of the spectrophotometric grade were used without further purifications.

\section{Light Scattering Apparatus}

Figure 1 shows a schematic diagram of the high temperature LS apparatus constructed in this work. The LS cell is made of an optically polished quartz tube with a diameter of about $6 \mathrm{~mm}$, as shown in Figure 2. The cell is fixed in a cell holder made of aluminum, a cross section of which is schematically shown in Figure 3. The cell holder, which is coated with a heat-resistant black paint (Fine Chem. Co., Japan), has 24 light traps on its inner wall to absorb stray lights. The aluminum cell holder is contained in another aluminum block and is placed in an air thermostat at $220^{\circ}$. To avoid the effect of expansion or distortion of the materials used, moreover, the aluminum cell holder is fixed on an independent stand made of a heat insulator rod (Micalex of $\mathrm{M}$. Watanabe \& Co., Ltd.), whose height is adjustable. The focusing of laser light beam on the quartz cell can, therefore, be adjusted from

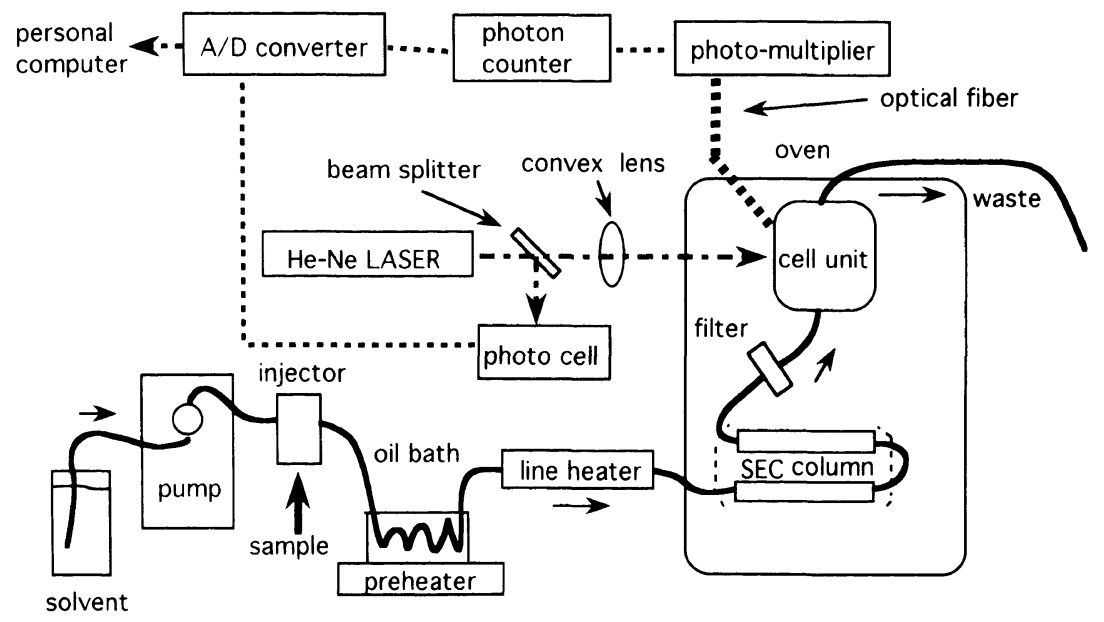

Figure 1. A high temperature light scattering apparatus. 


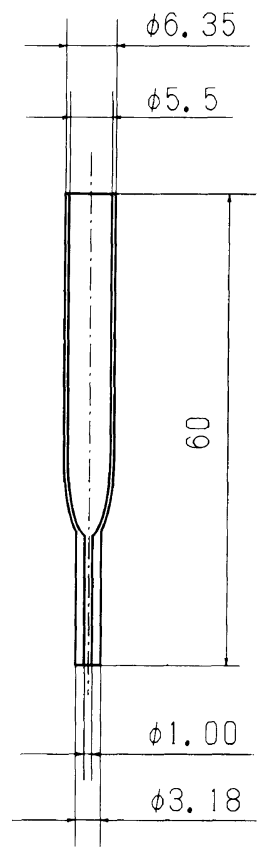

Figure 2. A LS cell made of quartz.

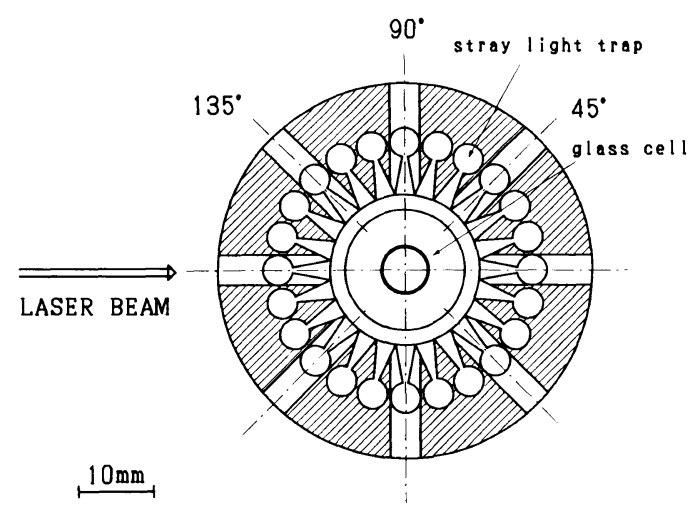

Figure 3. A cross section of the cell holder, shown schematically. The cell holder is made of aluminum, coated black, and has 24 traps for stray light on the wall. It is contained in another aluminum block with diameter of $100 \mathrm{~nm}$ and placed in the air thermostat.

outside of the thermostat, looking at the cell through a glass window. Most other materials used for construction of the system, such as stainless steel tubes or nuts and bolts, are those commonly used for liquid chromatography.

The present LS cell was designed for use in connection with SEC columns as shown in
Figure 1, but the SEC experiments were not carried out in the present work.

The solvent, 1-chloronaphthalene, is flowed into the LS cell at a constant speed with a high pressure pump (Tosoh CCPD). The temperature of the solvent is raised to $220^{\circ} \mathrm{C}$ by a line heater before entering the air thermostat. More than $3.5 \mathrm{ml}$ of 1-chloronaphthalene solution of sample PPS in the slurry state is injected into the solvent flow at room temperature using an injector valve (Reodyne 7125). The slurry is converted to a clear solution while it passes through a stainless steel tube of $6 \mathrm{~m}$ in an oil bath kept at $250^{\circ} \mathrm{C}$. The solvent and solution are passed through a Milipore FHUP (pore size $0.45 \mu \mathrm{m}$ ), before entering the LS cell.

A randomly polarized light beam from a $\mathrm{He}-\mathrm{Ne}$ laser (NEC GLG $5230 \lambda=632.8 \mathrm{~nm}$, $1 \mathrm{~mW})$ is irradiated into the cell and the scattered lights at $45^{\circ}, 90^{\circ}$, and $135^{\circ}$ are guided to a photon counter through an optical fiber glass of $0.6 \mathrm{~mm} \phi$ with a pinhole of $0.5 \mathrm{~mm} \phi$ at the top. The photon counting is carried out with a photomultiplier R649 and counter C-1230 of Hamamatsu Photonics, Ltd. The laser beam intensity is monitored using a beam-splitter and a photo-diode (S1226-8BK of Hamamatsu Photonics). The data from the photon counter and the monitor are sent to a personal computer (NEC PC-9801 VX21) through a A/D converter (Microscience, DAS-1298BPC-16). The data processing was carried out with a home-made and commercial programs.

TSK standard PS with $M_{w}=4.39 \times 10^{4}$ were used as references for determination of the instrumental constant of the LS apparatus constructed.

\section{Intrinsic Viscosity and Size Exclusion Chroma- tography}

The measurements of intrinsic viscosity $[\eta]$ and size exclusion chromatography (SEC) were carried out by Obasa in Polymer Research Laboratories, Tosoh Co., Ltd. Intrinsic viscosity $[\eta]$ was measured using a Ubelohde 
Table I. Weight-average molecular weight and intrinsic viscosity of PPS in comparison with SEC data ${ }^{a}$

\begin{tabular}{cccc}
\hline PPS No. & {$[\eta] / \mathrm{dlg}^{-1}$} & $M(\mathrm{SEC})\left(\times 10^{-4}\right)$ & $M_{w}\left(\times 10^{-4}\right)$ \\
\hline 1 & 0.20 & 2.5 & 1.7 \\
2 & 0.21 & 2.6 & 2.2 \\
3 & 0.28 & 3.7 & 3.6 \\
4 & 0.37 & 6.4 & 4.7 \\
5 & 0.41 & 7.1 & 5.9 \\
B1 & 0.13 & 3.5 & 9.8 \\
B2 & 0.20 & 2.8 & 5.1
\end{tabular}

${ }^{a} M_{w}$, weight-average molecular weight determined by LS.

$M$ (SEC), molecular weight determined by SEC, using TSK standard poly(styrene)s as reference.

viscometer in an oil bath at $220^{\circ} \mathrm{C}$. SEC data were obtained with a home-made high temperature SEC apparatus, using two columns of TSK gel GMH-XL-HT for high tempeature use at $220^{\circ} \mathrm{C}$. The detector used was a Soma Optics S-3750 UV/Vis absorption detector, ${ }^{8)}$ and the reference polymers used were TSK standard PS. The values of $[\eta]$ and the molecular weights thus estimated by SEC are listed in Table I.

\section{RESULTS AND DISCUSSION}

A few examples of measurements of scattered light intensity are shown in Fig. 4. Figure 4(a) shows the data for a standard PS in toluene at $30^{\circ} \mathrm{C}$, at angle $90^{\circ}$, while (b) and (c) show the data at $45^{\circ}$ and $135^{\circ}$ for PPS in 1chloronaphthalene at $220^{\circ} \mathrm{C}$, respectively. The base line shows the scattered light from the solvent, while the plateau shows the scattered light from the sample solution, so that the difference gives an increase in scattered light due to the solute $\left[\Delta i(\theta) / I_{0}\right]$ at the angle $\theta$. Since a larger volume of the sample solution was injected in experiment (c) than in (a) and (b), wider plateau is observed in (c). Observed values of photon counting on the base line and the plateau are, respectively, averaged in computer. Much more than $10^{4}$ counts were
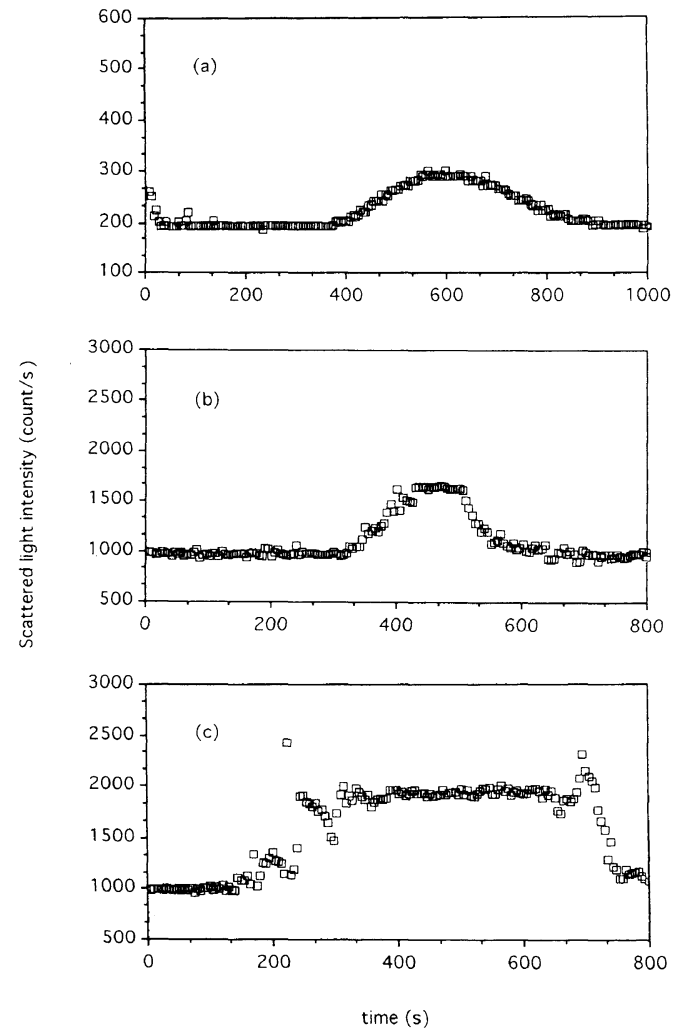

Figure 4. Examples of scattered light intensity measurements. (a) Poly(styrene) $\left(M_{w}=3.79 \times 10^{4}\right)$ in toluene at $30^{\circ} \mathrm{C}$. Conc., $3.16 \times 10^{-3} \mathrm{~g} \mathrm{~cm}^{-3}$. Injected volume, $3.5 \mathrm{ml}$. Angle, $90^{\circ}$. (b) PPS (No. 3) in 1-chloronaphthalene at $220^{\circ} \mathrm{C}$. Concn, $3.72 \times 10^{-3} \mathrm{~g} \mathrm{~cm}^{-3}$; injected volume, $3.5 \mathrm{ml}$; angle, $45^{\circ}$. (c) PPS (No. 5) in 1-chloronaphthalene at $220^{\circ} \mathrm{C}$. Concn, $4.41 \times 10^{-3} \mathrm{~g} \mathrm{~cm}^{-3}$, injected volume, $5.0 \mathrm{ml}$; angle, 135 .

used for the averaging. Abnormally large values, which are sometimes found as shown in Figure 4 (c), are omitted assuming that they are caused by dusts or some other reasons. If the concentration is high, abnormality is sometimes found when the sample concentration in the flow is changed.

The polymer concentration dependence of reduced scattering intensity $R(\theta)$ is given by 9

$$
\begin{aligned}
K C / R(\theta)= & 1 /\left[M_{w} \cdot P(\theta)\right] \\
& +2 A_{2} C+3 A_{3} C^{2}+\cdots
\end{aligned}
$$

where

$$
R(\theta)=\Delta i(\theta) r^{2} /\left[I_{0} \cdot V(\theta)\right]
$$




$$
K=2 \pi^{2} n_{0}^{2}(\mathrm{~d} n / \mathrm{d} C)^{2} / N_{\mathrm{A}} \lambda^{4}
$$

and $P(\theta)$ is the particle scattering factor, $A_{2}$ and $A_{3}$ are the second and third virial coefficients, respectively, and $C$ is the polymer concentration. Moreover, $V(\theta)$ is the scattering volume, $r$ the distance between the solution and the detector, $n_{0}$ the refractive index of solvent, $\mathrm{d} n / \mathrm{d} C$ the refractive index increment of solution, $\lambda$ the wave length of light in vacuo and $N_{\mathrm{A}}$ is Avogadro's number. If we define $\Delta G(\theta)$ by

$$
\Delta i(\theta) /\left[I_{0} \cdot V(\theta)\right]=\Delta G(\theta)
$$

where $\Delta i(\theta) / I_{0}$ is determined by experiments in Figure $4, R(\theta)$ is related to $\Delta G$ by

$$
R(\theta)=\Delta G(\theta) / \Phi
$$

where $\Phi$ is the instrumental constant. Since the molecular weights of the present samples are very low, their $P(\theta)$ are expected to be close to unity. If $P(\theta)$ is close to unity, using the assumption of Flory, ${ }^{10)}$ eq 1 can be transformed into ${ }^{11}$

$$
[K C / \Delta G(\theta)]^{1 / 2}=\left[1 /\left(\Phi \cdot M_{w}\right)\right]^{1 / 2}\left(1+A_{2} M_{w} C\right)
$$

The instrumental constant at $30^{\circ} \mathrm{C}$ was determined from eq 6 by measuring $\Delta G(\theta) / I_{0}$ of standard PS in toluene and benzene. The molecular weights of the standard PS used were low enough to assume $P(\theta)=1.0$. Figure 5 shows examples of $[K C / \Delta G(\theta)]^{1 / 2} v s . C$ plots for a PS at $30^{\circ} \mathrm{C}$. The $(\mathrm{d} n / \mathrm{d} C)$ for polystyrene in benzene and toluene at $30^{\circ} \mathrm{C}$ were assumed to be equal to the values at $25^{\circ} \mathrm{C}$ in literature. ${ }^{12}$

The instrumental constant for 1-chloronaphthalene at $220^{\circ} \mathrm{C}$ was estimated from the value at $30^{\circ} \mathrm{C}$ using the following relationship. ${ }^{13}$

$$
\Phi_{x}=\Phi_{y}\left(n_{x} / n_{y}\right)^{2}
$$

where $\Phi_{x}$ and $\Phi_{y}$ are the instrumental constants for solvents $x$ and $y$ at measuring temperatures, while $n_{x}$ and $n_{y}$ are the refractive indexes of those solvents at the temperatures, respectively. The refractive index of 1-chloronaphthalene at a temperature $T\left({ }^{\circ} \mathrm{C}\right)$ for $\lambda=632.8 \mathrm{~nm}$ may be calculated from

$$
n_{x}=1.633-4.6 \times 10^{-4}(T-20.0)
$$

which was determined for Na-D line $(\lambda=589$ $\mathrm{nm}) .{ }^{14}$ The refractive indexes of toluene and benzene can also be found in literature. ${ }^{12}$

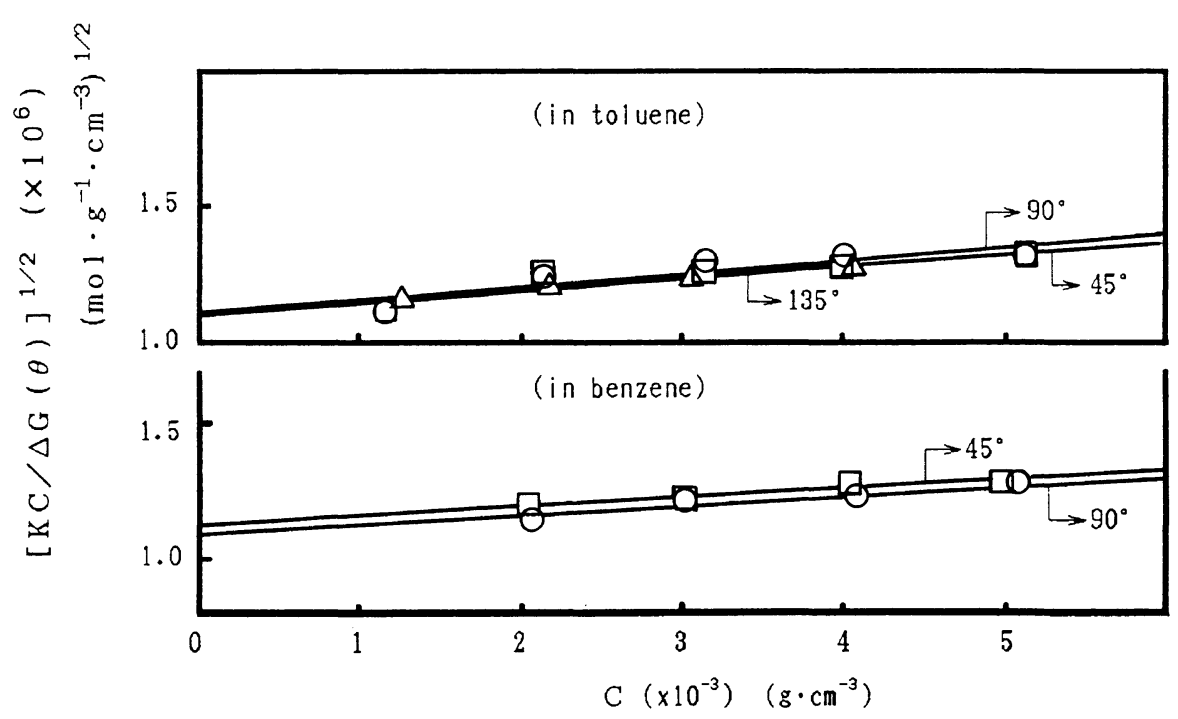

Figure 5. Examples of $(K C / \Delta G)^{1 / 2} v s$. $C$ plots at different angles for PS $\left(M_{w}=3.79 \times 10^{4}\right)$ in benzene and toluene at $30^{\circ} \mathrm{C}$. Angles are shown in the figure. 


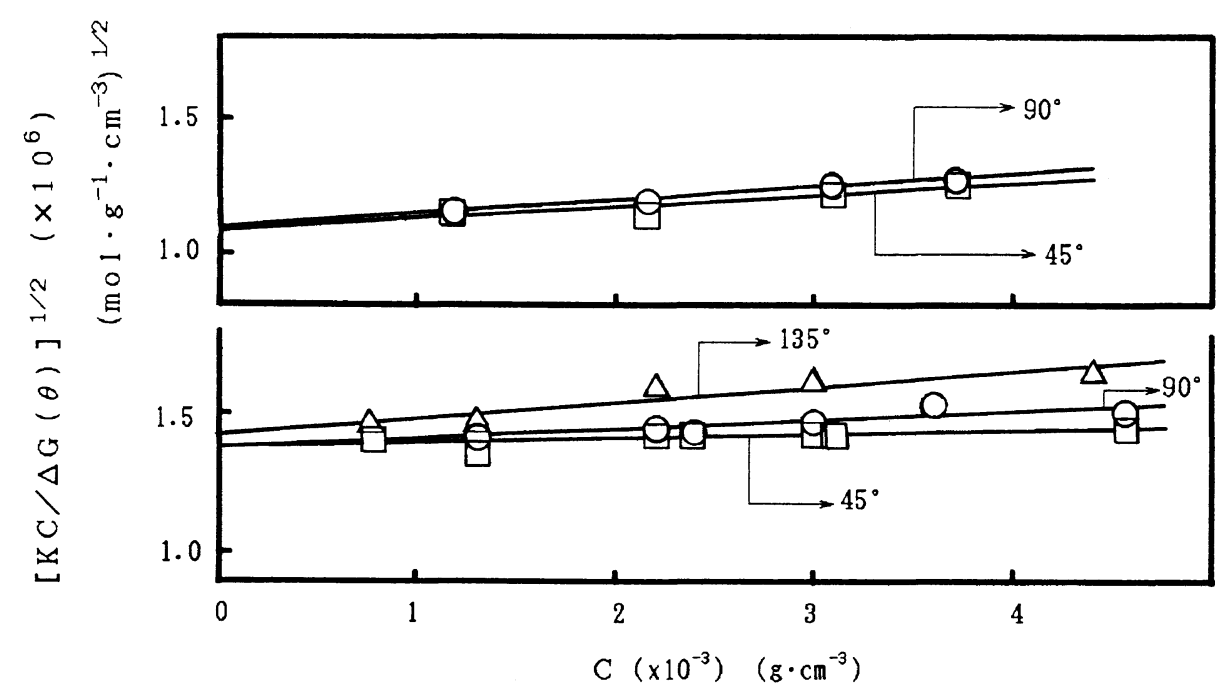

Figure 6. Examples of $(K C / \Delta G)^{1 / 2}$ vs. $C$ plots at different angles for PPS (upper, No. 3; lower, No. 5). in 1-chloronaphthalene at $220^{\circ} \mathrm{C}$. Angles are shown in the figure.

Table II. Comparison of molecular weights determined at different angles

\begin{tabular}{ccc}
\hline PPS No. & Angles $/{ }^{\circ}$ & $M_{w}\left(\times 10^{-4}\right)$ \\
\hline \multirow{2}{*}{3} & 90 & 3.6 \\
& 45 & 3.7 \\
\cline { 2 - 3 } 5 & 90 & 5.9 \\
& 45 & 5.8 \\
& 135 & 5.9 \\
\hline
\end{tabular}

Moreover, the change of concentration with temperature in 1-chloronaphthalene may be calculated using the volume expansion factor of 1 -chloronaphthalene $2.52 \times 10^{-4} /{ }^{\circ} \mathrm{C}$. ${ }^{15}$ The concentration at $220^{\circ} \mathrm{C}$ is about $5 \%$ lower than that at $30^{\circ} \mathrm{C}$. The instrumental constants at three angles in 1-chloronaphthalene at $220^{\circ} \mathrm{C}$ thus determined agreed with each other within a reasonable range, such as $2.11,2.12$, and $1.90 \times 10^{7}$ at $45^{\circ}, 90^{\circ}$, and $135^{\circ}$, respectively.

Figure 6 shows examples of $[K C / \Delta G(\theta)]^{1 / 2}$ vs. $C$ plots at three different angles for a PPS in 1-chloronaphthalene at $220^{\circ} \mathrm{C}$. The $(\mathrm{d} n / \mathrm{d} C)$ for 1-chloronaphthalene solution of PPS at $220^{\circ} \mathrm{C}$ is already reported by Stacy; ${ }^{6}$ i.e., $\mathrm{d} n / \mathrm{d} C=0.167 \mathrm{~cm}^{3} \mathrm{~g}^{-1}$. The limiting values at

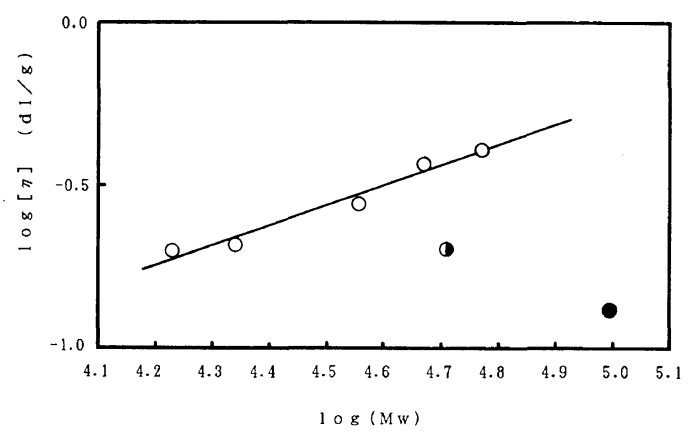

Figure 7. Intrinsic viscosity-molecular weight relationship of PPS in 1-chloronaphthalene at $220^{\circ} \mathrm{C}$. Open circles show the data for linear PPS, while filled and half-filled circles show the data for the filtered sample of No. B1 (heat-treated) and a branched sample No. B2, respectively.

$C=0$ in Figure 6 and the instrumental constants $\Phi$ at each angle give $M_{w}$ of the sample. The values of $M_{w}$ obtained at three different angles agree with each other within the error of 3\%, a shown in Table II. Since most PPS samples available at present have low molecular weights, it may be concluded that their $M_{w}$ can safely be determined from measurements at an angle. $M_{w}$ of all other samples beside Nos. 3 and 5 were determined from measurements at $90^{\circ}$ only. 
In Table I and in Figure 7, the weightaverage molecular weights of five linear PPS thus determined are compared with their intrinsic viscosities $[\eta]$. The $\log [\eta]-\log M_{w}$ relationship determined by the least mean square method is

$$
[\eta]=4.73 \times 10^{-4} M_{w}^{0.62}
$$

and its correlation factor $R$ is 0.98 .

The data for a heat-treated PPS No. B1, which was purified by filtation as explained in Experimental section, and also for a branched PPS No. B2 are also shown in Figure 7. The values of $[\eta]$ of Nos $B 1$ and $B 2$ are found to be much lower than the values of linear polymers with the same molecular weights. It is clear that heat-treated PPS molecules are branched or cross-linked.

In Table I, moreover, the weight-average molecular weights $M$ (SEC) of the present samples estimated from high temperature SEC using standard PS as reference are compared with $M_{w}$ determined by LS in this work. It is reasonable that $M(\mathrm{SEC})$ is much lower than $M_{w}$ for branched PPS. In the case of linear PPS, on the other hand, SEC gives higher molecular weights than LS. In other words, the elution volume $V_{e}$ of linear PPS is smaller than $V_{e}$ of PS with the same $M_{w}$ so that the hydrodynamic volume of PPS may be larger than that of a corresponding PS. It is probably because PPS has a stiffer backbone than PS.

Acknowledgement. We wish to thank To- soh Co., Ltd. for supplying the samples with intrinsic viscosity and other data and, in particular, Mr. Masatoshi Nagata for his encouragements and arrangements. The authors are highly indebted to Mr. Tsuyoshi Habe for his work in our preliminary study.

\section{REFERENCES}

1. H. A. Smith and C. E. Handlovits, "Phenylene Sulphide Polymers," Part I and II Aeronautical Systems Div., Air Force Systems Command, Fairborn, Ohio, 1962.

2. R. M. Black, C. F. List, and R. J. Wells, J. Appl. Chem., 17, 269 (1967).

3. G. F. L. Ehlers, K. R. Fisch and W. R. Powell, J. Polym. Sci., A-1, 7, 2955 (1969).

4. H. L. Hill, Jr. and J. T. Edmonds, Jr., Adv. Chem. Ser., 129, 80 (1973).

5. J. N. Short and H. W. Hill, Jr., Chem. Technol., 481 (1972).

6. C. J. Stacy, J. Appl. Polym. Sci., 32, 3959 (1986).

7. A. Kinugawa, Kobunshi Ronbunshu, 44, 139 (1987).

8. T. Housaki and K. Satoh, Polym. J., 20, 1163 (1988).

9. M. B. Huglin, Ed., "Light Scattering from Polymer Solution,” Academic Press, London, 1972.

10. P. J. Flory, "Principles of Polymer Chemistry," Cornell University Press, Ithaca, N. Y., 1953.

11. G. C. Berry, J. Chem. Phys., 44, 4550 (1966).

12. J. Brandrup and E. H. Immergut, Ed., "Polymer Handbook," John Wiley \& Sons, New York, N. Y., 1975.

13. J. J. Hermans and S. Levinson, J. Opt. Sci. Am., 41, 460 (1951).

14. C. J. Stacy and R. L. Arnett, J. Polym. Sci., A, 2, 167 (1964).

15. Kirk-Othmer, "Encyclopedia of Chemical Technology," Vol. 5, 2nd ed, Wiley, N. Y., 1964. 